Books, videos, cd-roms, dvds and any other relevant items submitted for a review in the BDJ should be addressed to:

Mike Grace, Editor, British Dental Journal, 64 Wimpole Street WIG 8YS

\section{Sedation and analgesia for diagnostics and therapeutic procedures}

S.Malviga, N.N Naughtun and K.K. Tremper (ed) New Jersey: Humana Press, 2003

price US\$125, pp310

ISBN 0896038637

This book is an American text covering the practice of sedation and analgesia. It is primarily aimed at the nonanaesthetist sedation practitioner, covering a wide range of medical specialties.

The first chapter of the book covers current theories of sedation and is titled 'Opioids, sedation and sleep' -although opioids are not especially singled out for special mention. However, this review is undoubtedly well referenced, as is the rest of the book. Subsequent chapters then concentrate on paediatric and adult guidelines and site-specific sedation techniques. These are directed exclusively at the American system and are of little relevance to UK practitioners of sedation techniques. Even specific references to dentistry are outside the GDC definition of conscious sedation and would fall into the realms of general anaesthesia. There is little reference to the use of local anaesthesia as an adjunct to sedation. This highlights the fact the American definition of sedation is a continuum between light sedation and general anaesthesia and is further clouded with the concurrent use of centrally acting analgesics. This is borne out by a whole chapter on how to assess the depth of sedation by a myriad of different scoring systems. Later chapters discuss monitoring, pharmacology and nursing aspects of sedation practice. The final chapter involves developing quality assurance systems.

This book has little relevance to the UK practice of dental outpatient sedation by non-anaesthetists. Even specific references to dentistry reflect very much the American style of sedation practice.
It may be of interest to research fellows or anaesthetists as a source of references. J. Lyne

\section{Oral and maxillofacial pathology: a rationale for diagnosis and treatment}

\author{
R. E. Marx and D. Stern \\ Surrey: Quintessence Books \\ price £283, pp908 \\ ISBN 0867153903
}

As would be expected from these publishers this is a large and beautifully presented textbook. Despite the title, this is not a book for pathologists but for clinicians of all sorts and is thus concerned with pathology in its broadest sense, including a consideration of the clinical presentation, mechanisms, management, and histopathology of diseases of the head and neck. The authors have high ambitions and state in the preface that the book is intended to be a 'clinically oriented and forwardlooking guide for oral and maxillofacial surgeons' and that they wish to challenge 'established concepts and dogmas currently prevailing in oral and maxillofacial pathology and surgery' and to 'simplify and streamline terminology'. I therefore expected a refreshing re-appraisal and update on some lesions. It was with some dismay, therefore, that in the first major chapter, I noted their use of dated terminology such as 'epulis fissuratum' and 'peripheral ossifying fibroma' - terms long since deleted from common usage in the UK.

The section on the terminology of ameloblastoma, which attempts to clarify understanding of this lesion is unfortunately too confusing to be helpful. While many would agree that the classification of cystic ameloblastoma requires serious revision, the authors' reclassification into in situ, microinvasive and invasive subtypes leads to even more confusion - this section needs a serious rethink. Unfortunately, therefore the authors' attempts to rationalise terminology have not been met, some outdated terms are still used and many of the terms heralded as new in Chapter 20 have been in common usage for some time.

Overall however, the book presents a thorough overview of the presentation and management of disorders and diseases of the maxillofacial regions. It is extremely comprehensive, covering almost every conceivable condition in 20 chapters. The first 19 chapters are arranged by fairly conventional classifications, for example 'Inflammatory reactive and infectious diseases', 'Odontogenic tumours' etc. with a final chapter discussing current and new terminology. Each condition is considered in a logical format, including sections on clinical presentation, pathogenesis, differential diagnosis, diagnostic work-up, histopathology and treatment and prognosis. Most chapters also have sections on principles of management and sometimes detailed considerations of surgical technique. Unfortunately, the text is not referenced, so many statements and the evidence for some of the claims and terminologies cannot be attributed. A bibliography is provided at the end of the book, by chapter number, but unfortunately this is not well synchronised and some of the chapter headings are wrong.

The text is well laid out and is accompanied by useful tables and excellent quality clinical and microscopic photographs. Clear and well-drawn diagrams are frequently used to explain the mechanisms of disease and clinicopathological correlations. For example the development of cysts, their histopathology and radiological or clinical presentations are beautifully illustrated in a table of diagrams and photographs.

In summary, this is an extremely comprehensive text and a worthy 

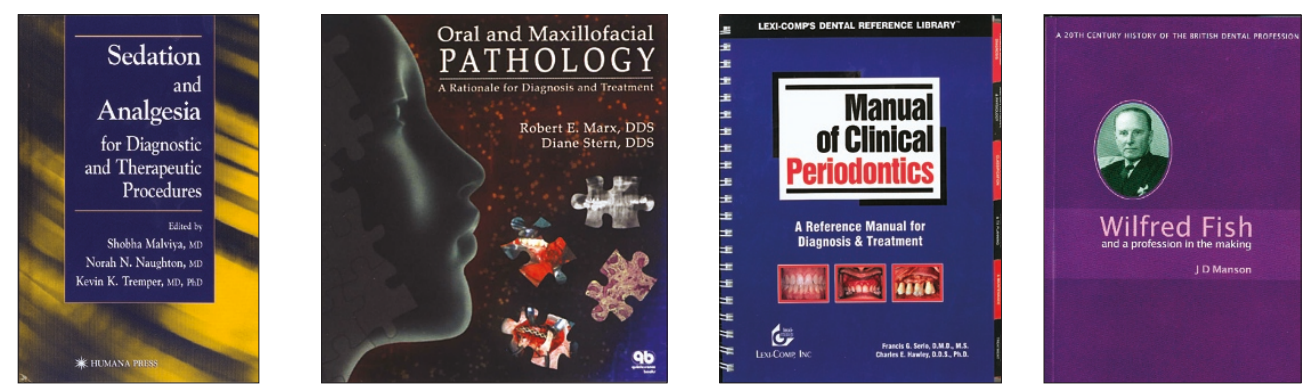

attempt to present an integrated consideration of pathologies affecting the head and neck. However it can confuse, since some of the terminologies and classifications are either outdated or new, and for a critical post-graduate reader there are no references to justify or provide the evidence for statements in the text. I can give the book a cautious welcome and would thoroughly recommend it for selected reading as part of a course. In time however I believe this book will become increasingly popular especially if some of the problems are ironed out in a second edition. P. Speight

\section{Manual of clinical periodontics}

F. G. Serio and C. E. Hawley

Hudson: Lexi-Comp inc

price: US\$54.95, pp146

ISBN 1930598823

Periodontics has numerous text books for all members of the dental team. This entirely new book takes a refreshingly different approach to the subject.

The contents are presented in a 'question and answer' format, ensuring that each subject area is described step-by-step, easily satisfying the authors' aim of providing a reference manual for both the clinical and academic setting. The reader can imagine how beneficial this approach is, as these questions are repeatedly asked by interested patients and examiners alike.

The book is certainly easy to use. It is spiral bound, with chapters separated in a tabular form. The paper quality is excellent and there is widespread use of high quality clinical photographs, line drawings and diagrams. The text is clearly written and presented, without attempting to provide a comprehensive review of each subject area. Where this is appropriate, the reader is directed to a comprehensive list of upto-date references.

All the expected subject areas within periodontics are present and, in addition, the authors have included a very useful final section, detailing such matters as 'dental drug interaction' and the contents of 'dentifrice products'.

The authors are both American and there are some aspects of the book that reveal this. In addition, as with every textbook, the keen-eyed reader can find fault with some minor details and omissions. However, these matters do not detract from what is clearly an excellent new addition to periodontal literature. I have allowed several colleagues including dental hygienists, undergraduate and post-graduate dental students and specialist periodontists to review this book and all have expressed a firm interest in using it in the future. I have encouraged them to buy their own. M. Ashley

\section{Wilfred Fish and a profession in the making}

\section{JD Manson}

12 Wheatley St, London, W1G 8PS, 0207935 4209, hildavid@btinternet.com. 2003.

price: £24, pp265

ISBN 0953610217

Dr Manson's welcome biography of Sir Wilfred Fish is plainly the result of a lot of research, and delivers valuable insights into the life of a complex and driven man. The first chapters put the young Wilfred Fish in his context, and the introduction is a summary of the distance the profession has travelled since the early 19 th century. Each later chapter is devoted to one area of major achievement or conflict in his professional and personal life.

The book records how Sir Wilfred, one of the giants in dental affairs in the last century, who retired in 1961 and died at the age of 80 in 1974, shaped the profession. The record is impressive, his work on prosthetics and periodontics was valuable, and he was also remarkable as a researcher and fundraiser for research. His political record was one of achievement, and as first Chairman of the General Dental Council in 1956, he oversaw the freeing of dentistry from medical administration.

It is curious that this man, with his immense earnings from his profession, a medical qualification, a more than adequate intellectual ability, a most distinguished patient list, membership of the Athenaeum, and a Knighthood, still comes across as 'chippy' about dentistry. The reader is left asking which of his character traits and social attributes pushed Sir Wilfred onwards and which enabled him to achieve what he did for the profession.

The details of his domestic life make sad reading, and the photographs selected tell a story of eventual eclipse by Sir Robert Bradlaw, which may be intentional, or may be unconscious on the part of a biographer who has ended up in two minds about whether he likes his subject or not. Some of his contemporaries did not hide their feelings, so it comes as a relief to read of a grand-daughter who clearly loved him.

There are some errors with minor but easily checked things; 'Storkey' and 'Storky' for Kipling's Stalky for example, and no acknowledgement of Kipling's borrowing from Carroll make the reviewer itch for references to allow for checking of other more important quotations. The potential of the book as archival resource material is also very much affected by the absence of an index, and there is no bibliography of Fish's work. The reader has to use the chapter headings instead, but even here, without page headings it is not made easy to work the book. An important reference work has been lost by these omissions.

Nevertheless, this biography is instructive to the young practitioner, if a source of mixed feelings for the older, and should be required reading for any aspiring dental politician.

\section{Bishop}

